\title{
Effect of Nano - Titanium Dioxide with Different Antibiotics against Methicillin-Resistant Staphylococcus Aureus
}

\author{
Aashis S. Roy ${ }^{1}$, Ameena Parveen ${ }^{2}$, Anil R. Koppalkar ${ }^{3}$, M. V. N. Ambika Prasad ${ }^{1 *}$ \\ ${ }^{1}$ Department of Materials Science, Gulbarga University, Gulbarga, Karnataka, India; ${ }^{2}$ Department of Physics, Gurmithkal, Yadgir, \\ Karnataka, India; ${ }^{3}$ Materials Science Lab, S. S. Margol College, Shahabad, Gulbarga, Karnataka, India. \\ Email: *amb1_prasad@rediffmail.com
}

Received June $14^{\text {th }}, 2010$; revised June $25^{\text {th }}, 2010$; accepted June $30^{\text {th }}, 2010$.

\begin{abstract}
The different investigation has been carried out on the biological activities of titanium dioxide nanoparticle but the effect of this nano product on the antibacterial activity of different antibiotics has not been yet demonstrated. In this study the nano size $\mathrm{TiO}_{2}$ is synthesized using citric acid and alpha dextrose and the enhancement effect of $\mathrm{TiO}_{2}$ nanoparticle on the antibacterial activity of different antibiotics was evaluated against Methicillin-resistant Staphylococcus aureus (MRSA). During the present study, different concentrations of nano-scale $\mathrm{TiO}_{2}$ were tested to find out the best concentration that can have the most effective antibacterial property against the MRSA culture. Disk diffusion method was used to determine the antibacterial activity of these antibiotics in the absence and presence of sub inhibitory concentration of $\mathrm{TiO}_{2}$ nano particle. A clinical isolate of MRSA, isolated from Intensive Care Unit (ICU) was used as test strain. In the presence of sub-inhibitory concentration of $\mathrm{TiO}_{2}$ nanoparticle $(20 \mu \mathrm{g} /$ disc $)$ the antibacterial activities of all antibiotics have been increased against test strain with minimum $2 \mathrm{~mm}$ to maximum $10 \mathrm{~mm}$. The highest increase in inhibitory zone for MRSA was observed against pencillin $G$ and amikacin (each $10 \mathrm{~mm}$ ). Conversely, in case of nalidixic acid, $\mathrm{TiO}_{2}$ nanoparticle showed a Synergic effect on the antibacterial activity of this antibiotic against test strain. These results signify that the $\mathrm{TiO}_{2}$ nanoparticle potentate the antimicrobial action of beta lactums, cephalosporins, aminoglycosides, glycopeptides, macrolids and lincosamides, tetracycline a possible utilization of nano compound in combination effect against MRSA.
\end{abstract}

Keywords: Nano - Titanium Oxide, S. Aureus, Drug Resistance, Antibacterial Activity

\section{Introduction}

Methicillin-resistant Staphylococcus aureus (MRSA) is one of the major nosocomial pathogens responsible for a wide spectrum of infections, including skin and soft tissue infections, pneumonia, bacteraemia, surgical site infections (SSI), catheter related infections [1]. Intensive care unit characteristically has higher rates of infections and increased transmission rates, high antibiotic use and large numbers of vulnerable patients [2]. The emergence of bacterial resistance to antibiotics and its dissemination, however, are major health problems, leading to treatment drawbacks for a large number of drugs [3,4]. Consequently there has been increasing interest in the use of inhibitors of antibiotic resistance for combination therapy $[5,6]$.

Nanostructured materials are attracting a great deal of attention because of their potential of achieving specific processes and selectivity, especially in biological and pharmaceutical applications [7-9]. Gold, silver and copper have been used mostly for the synthesis of stable dispersions of nanoparticles [10,11]. A unique characteristic of these synthesized metal particles is that a change in the absorbance or wave length gives a measure of the particle size, shape and interparticle properties [12]. Nanomaterials are called "a wonder of modern medicine". It is stated that antibiotics kill perhaps a half dozen different disease-causing organisms but nanomaterials can kill some 650 cells [13]. Resistant strains fail to develop if we apply nanoparticles based formulations in their culture media.

The antibacterial activity of $\mathrm{TiO}_{2}$ has been found to be due to a reaction of the $\mathrm{TiO}_{2}$ surface with water. On exposure to ultraviolet (UV) irradiation, $\mathrm{TiO}_{2}$ releases free radicals such as $\mathrm{OH}, \mathrm{O}_{2}^{-}, \mathrm{HO}_{2^{-}}$, and $\mathrm{H}_{2} \mathrm{O}_{2}$. This 
potent oxidizing power characteristically results in case of bacteria and other organic substances [14-16]. The small nanometer-scale $\mathrm{TiO}_{2}$ particles impose several effects that govern its antibacterial action we examined the antimicrobial activity of nanostructured titanium dioxide with different antibiotics against MRSA. The different investigation has been carried out on the biological activities of titanium dioxide nanoparticle but the combination effects of this product with different antibiotics have not been demonstrated. The nanocrystalline particles of $\mathrm{TiO}_{2}$ are synthesized using ultrasonic irradiation, and the particle sizes are controlled using different solvents during the sonication process.

Objectives of the present study are (i) synthesis of nano size titanium dioxide using citric acid and alpha dextrose (ii) analyse the effect of Titanium nanoparticles on the antibacterial activity of different antibiotics against MRSA (iii) estimation of MRSA growth in the presence of $\mathrm{TiO}_{2}$ nanoparticles have been reported having an extremely good safety profile and no toxicity observed when taken at different nanosize. Taken together, this compound as a highly safe compound may be considered for combination therapy against MRSA, due its potential synergetic effect with important antibiotics such as beta lactums, cephalosporins, aminoglycosides.

\section{Materials and Methods}

Titanium dioxide particles preparation: In the following, the two step sol-gel preparation method used is described detail. Nanocrystalline titanium dioxide was prepared by employing citric acid route were saturated solution of $\alpha$-Dextrose used as a surfactant.

Two separate solutions were prepared. In first step: titanium nitrate and citric acid are taken in 1:3 and are thoroughly stirred using magnetic stirrer with ammonia solution at $80^{\circ} \mathrm{C}$ about 5-6 hrs. Ammonia solution is used to maintain the $\mathrm{pH} 4$ of solution. Finally a gel is formed. In second step, saturated solution of alpha dextrose is added and stirred for $1 \mathrm{hr}$ at $120^{\circ} \mathrm{C}$ to the spongy type gel of nanoscaled $\mathrm{TiO}_{2}$ formed. This spongy gel is ignited at a temperature of about $300^{\circ} \mathrm{C}$ for $1 \mathrm{hr}$. At this temperature a combustion process takes place in the spongy gel containing citric acid a result of it we have nanostructured titanium dioxide.

\section{X-Ray Diffraction (XRD)}

$\mathrm{X}$-ray diffraction Phase identification was carried out by $\mathrm{X}$-Ray powder diffraction at ambient temperature. A Shintag $\mathrm{X} 1$ diffractometer with $\mathrm{Cu} \mathrm{K \alpha}(1.54 \mathrm{~A})$ radiation in $\theta-\theta$ configuration was used. The patterns were recorded in the 2-70 range at 0.05 step size using 3-s acquisition time per step. The mean particle size was calculated using the Debye-Scherrer Equation 1 in which
$\mathrm{K}$ is a constant equal to $0.9, \lambda$ is the wavelength of the $\mathrm{Cu}$ $\mathrm{K} \alpha$ radiation, $\beta$ is the half peak width of the diffraction peak in radiant and $\theta$ is the Braggs angle of (311) plane.

$$
\tau=\mathrm{K} \lambda / \beta \cos \theta
$$

Staphylococcus aureus was isolated from Clinical specimens collected from ICU of Durgabai Deshmukh Hospital and Research Center and Osmania Hospital, Hyderabad, South India. Oxacillin-disc diffusion method was done for identification of methicillin-resistance. This MRSA was used as test strain. Antibiotic susceptibility test was performed for the test strain (MRSA) against 23 antibiotics by disc agar diffusion method (DAD) on Muller-Hinton agar (Himedia, India), according to the guidelines recommended by National Committee for Clinical Laboratory Standards (NCCLS) [17].

\section{Disk Diffusion Assay to Evaluate Combined Effects}

To determine combined effects, each standard paper disc was further impregnated with sub-inhibitory concentration of titanium dioxide nanoparticle $(10 \mu \mathrm{g} / \mathrm{disc})$. A single colony of test strains were grown overnight in Muller-Hinton broth medium on a rotary shaker (200 rpm) at $35^{\circ} \mathrm{C}$. The inoculums were prepared by diluting the overnight cultures with $0.9 \% \mathrm{NaCl}$ to a $0.5 \mathrm{McF}$ arland standard and were applied to the plates along with the standard and prepared disks containing of titanium dioxide nanoparticle $(10 \mu \mathrm{g} / \mathrm{disc})$. Clinical isolates of MRSA from our culture collection were used as test strains. After incubation at $37^{\circ} \mathrm{C}$ for $24 \mathrm{hrs}$, the zones of inhibition were measured. The assays were performed in triplicate.

\section{Estimation of MRSA Growth in the Presence of Nanocrystalline $\mathrm{TiO}_{2}$}

The $2 \mathrm{~mL}$ of the overnight-cultured MRSA was added to $100 \mathrm{~mL}$ nutrient broth, containing $0.12 \%$ glucose with and without $0.01,0.5$ and $1 \%$ nano- $-\mathrm{TiO}_{2}$ and incubate at $30^{\circ} \mathrm{C}$ for $24 \mathrm{hrs}$. Optical density measurements were taken at $600 \mathrm{~nm}$ to monitor the bacterial concentration.

\section{Results and Discussions}

The nano size titanium dioxide is synthesized using citric acid and alpha dextrose. The small nanometer scale $\mathrm{TiO}_{2}$ particles as seen in the Figure 1 will impose several effects that govern its antibacterial action. The X-ray diffraction pattern shows cubic peaks of $\mathrm{TiO}_{2}$, which indicates the nanocrystalline nature of pure nanostructured titanium dioxide and is shown in the Figure 2. By comparing the XRD pattern standard JCPS data (432-161) of $\mathrm{TiO}_{2}$, indicating the prominent peaks corresponding to $2 \theta=27^{\circ}, 39^{\circ}, 48^{\circ}, 55^{\circ}$ and $63^{\circ}$ are due to (110), (200), (112), 


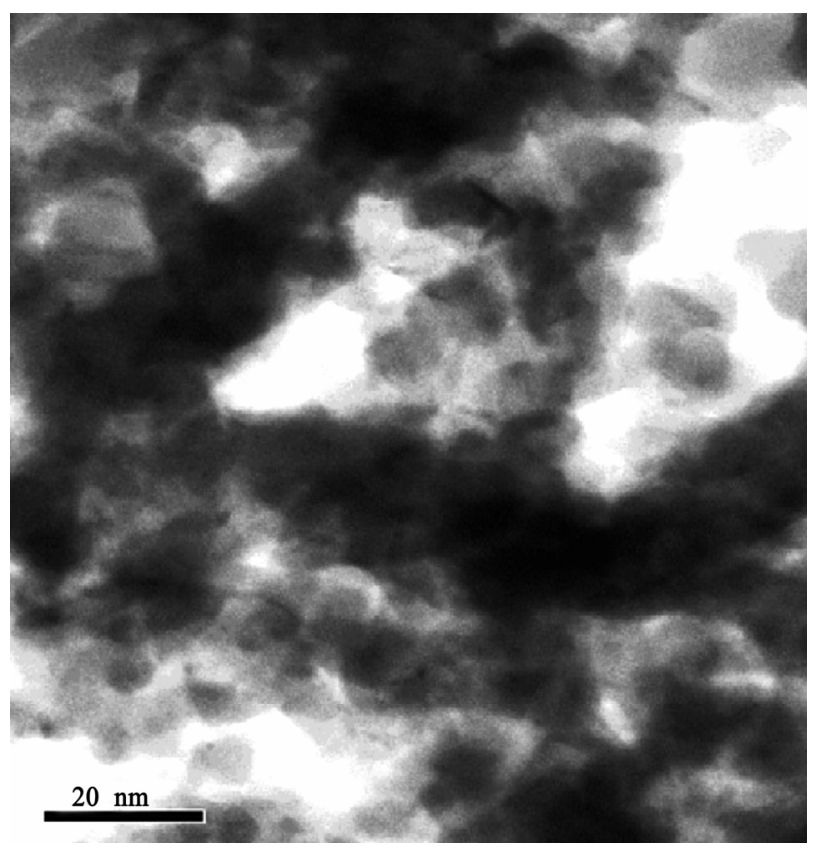

Figure 1. Showing TEM image of $\mathrm{TiO}_{2}$ nanoparticles.

(220) and (310) planes which indicates formation of single phase titanium dioxide. The crystalline size of the Titanium dioxide is calculated by using debye-scharrer equation and it was found to be around $20 \mathrm{~nm}$. Titanium dioxide has a very good potential to move into the clinic [18]. In this investigation the effect of $\mathrm{TiO}_{2}$ nanoparticle on the antibacteria of different antibiotics was investtigated against MRSA using disk diffusion method. The antimicrobial resistance of MRSA against various antibiotics is increased without nano- $\mathrm{TiO}_{2}$ and decreases with nanoscaled $\mathrm{TiO}_{2}$. The diameter of inhibition zones $(\mathrm{mm})$ around the different antibiotic discs with $\mathrm{TiO}_{2}$ and without titanium dioxide nanopatrticles against test strain are shown in [Table 1].

The antibacterial activities of all antibiotics have been increased in the presence of nanosize titanium dioxide against test strain. The highest antibacterial activities increases in area were observed for penicillin and amikacin (10 $\mathrm{mm})$ followed by ampicillin and Gentamycin (in each $09 \mathrm{~mm})$, oxacillin, cloxacillin (08 mm), amoxycillin, cephalexin, cefotoxime, ceftazidime, vancomycin, streptomycin (in each $07 \mathrm{~mm}$ ) erythromycin, clindamycin (06 $\mathrm{mm})$ and tetracyclin $(05 \mathrm{~mm})$. The moderate increases in inhibition zone areas for ciprofloxacin, rifampicin, sulphazidime and cotrimoxazole $(04 \mathrm{~mm})$. The lowest increase in inhibition zone area against the Chloramphenicol $(03 \mathrm{~mm})$ followed by norfloxacin and clarithromy$\operatorname{cin}(02 \mathrm{~mm})$.

Conversely, for nalidixic acid, titanium dioxide nanoparticle shows no effect on the antibacterial activity of

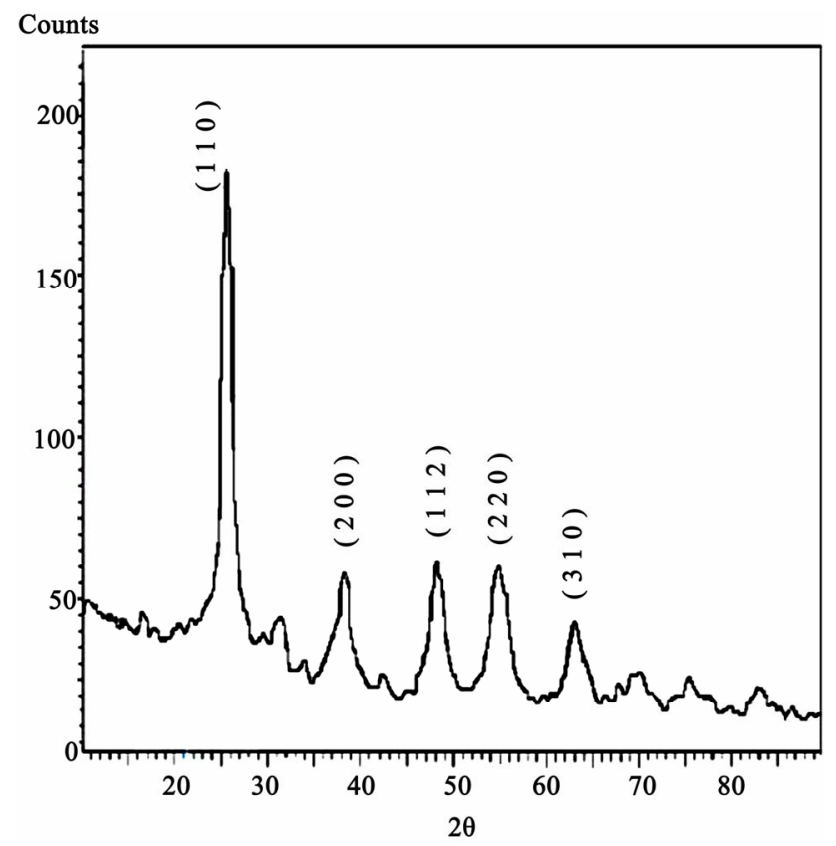

Figure 2. XRD pattern of $\mathrm{TiO}_{2}$.

this antibiotic against the test strain. It should be pointed out that the titanium dioxide nanoparticle content of 10 $\mu \mathrm{g} /$ disc was chosen to guarantee that the effect produced was due to the combination and not to the effect of the $\mathrm{TiO}_{2}$ nanoparticle itself. So the effect observed in this condition could be due to the antibiotic-titanium dioxide nanoparticle combination. At the concentration tested, $\mathrm{TiO}_{2}$ nanoparticle significantly improved antibiotic efficacy against $S$. aureus when combined with beta lactums, cephalosporins, aminoglycosides.

The optical density of the medium was investigated as the number of bacteria after contact with the nano- particles. Figure 3 shows the growth of MRSA at diff- erent concentrations and the effect of different $0.01,0.5$ and $1 \%$ nano- $\mathrm{TiO}_{2}$ on the in growth and killing of MRSA. As demonstrated by the figure, $0.01 \%$ nano- $\mathrm{TiO}_{2}$ did not have antibacterial efficiency on MRSA but the concentrations of 0.5 and $0.1 \%$ nano- $\mathrm{TiO}_{2}$ inhibited the bacterial growth. Also shows that $0.5 \%$ nano- $\mathrm{TiO}_{2}$ showed 1.9 times decrease the optical density of bacterial cultures as compared to the control. While, in the presence of $1 \%$ nano- $\mathrm{TiO}_{2}$, the optical density of MRSA cultures decreased 4.5 times as compared to the control experiment.

A study states the nano- $\mathrm{TiO}_{2}$ as a strong and effective bactericidal agent [18]. During the present study, different concentrations of nanosized $\mathrm{TiO}_{2}$ were tested to find out the best concentration that can have the most effective antibacterial property against the MRSA culture. This is the first report of combination effect of $\mathrm{TiO}_{2}$ nanoparticles with different antibiotics. Today, $\mathrm{TiO}_{2}$ 
Table 1. the comparative activities of various antibiotics and antibiotic with NanosizedTiO $_{2}$ against MRSA.

\begin{tabular}{|c|c|c|c|c|c|}
\hline $\begin{array}{l}\text { Sl. } \\
\text { No. }\end{array}$ & Antibiotics & Symbol & $\begin{array}{l}\text { Inhibition Zone of Antibiotic } \\
\qquad(\mathrm{mm})\end{array}$ & $\begin{array}{l}\text { Inhibition Zone of Antibiotic with } \\
\mathrm{TiO}_{2}(20 \mathrm{~nm}) \text { in }(\mathrm{mm})\end{array}$ & Increased zone size $(\mathrm{mm})$ \\
\hline 1 & B-lactams & & & & \\
\hline 01. & Penicillin G & $P(10 U)$ & 34 & 44 & 10 \\
\hline 02. & Oxacillin & $\mathrm{Wx}(1 \mu \mathrm{g})$ & 11 & 19 & 08 \\
\hline 03. & Cloxacillin & $\mathrm{Cx}(30 \mu \mathrm{g})$ & 19 & 27 & 08 \\
\hline 04. & Ampicillin & $\mathrm{A}(10 \mu \mathrm{g})$ & 29 & 38 & 09 \\
\hline $\begin{array}{c}05 . \\
2\end{array}$ & $\begin{array}{l}\text { Amoxycillin } \\
\text { Cephalosporins }\end{array}$ & Am $(25 \mu \mathrm{g})$ & 20 & 26 & 07 \\
\hline 06. & Cephalexin & $\mathrm{Cp}(30 \mu \mathrm{g})$ & 25 & 32 & 07 \\
\hline 07. & Cefotoxime & $\mathrm{CX}(30 \mu \mathrm{g})$ & 24 & 33 & 07 \\
\hline 08. & Ceftazidime & $\mathrm{Ca}(30 \mu \mathrm{g})$ & 16 & 23 & 07 \\
\hline 3 & Glycopeptides & & & & \\
\hline $\begin{array}{c}09 . \\
4\end{array}$ & $\begin{array}{l}\text { Vancomycin } \\
\text { Aminoglycosides }\end{array}$ & $\mathrm{V}(30 \mu \mathrm{g})$ & 15 & 22 & 07 \\
\hline 10. & Amikacin & Ak $(10 \mu \mathrm{g})$ & 15 & 25 & 10 \\
\hline 11. & Gentamycin & $\mathrm{G}(50 \mu \mathrm{g})$ & 14 & 24 & 09 \\
\hline 12. & Streptomycin & $\mathrm{S}(25 \mu \mathrm{g})$ & 13 & 19 & 07 \\
\hline 5 & Flouroquinolones & & & & \\
\hline 13. & Ciprofloxacin & $\mathrm{Cf}(5 \mu \mathrm{g})$ & 20 & 24 & 04 \\
\hline $\begin{array}{c}14 . \\
6\end{array}$ & $\begin{array}{l}\text { Norfloxacin } \\
\text { Azlides }\end{array}$ & No $(10 \mu \mathrm{g})$ & 15 & 17 & 02 \\
\hline $\begin{array}{c}15 . \\
7\end{array}$ & $\begin{array}{l}\text { Clarithromycin } \\
\text { Macrolides }\end{array}$ & $\mathrm{Cw}(15 \mu \mathrm{g})$ & 17 & 19 & 02 \\
\hline $\begin{array}{c}16 . \\
8\end{array}$ & $\begin{array}{l}\text { Erythromycin } \\
\text { Lincosamides }\end{array}$ & $\mathrm{E}(15 \mu \mathrm{g})$ & 15 & 21 & 06 \\
\hline $\begin{array}{c}17 . \\
9\end{array}$ & $\begin{array}{l}\text { Clindamycin } \\
\text { Sulphonamides }\end{array}$ & $\mathrm{Cl}(10 \mu \mathrm{g})$ & 20 & 26 & 06 \\
\hline 18. & Cotrimoxazole & Co $(25 \mu \mathrm{g})$ & 17 & 21 & 04 \\
\hline 19. & Nalidixicacid & $\mathrm{Na}(30 \mu \mathrm{g})$ & 16 & 16 & 00 \\
\hline 20. & Rifampicin & $\mathrm{R}(15 \mu \mathrm{g})$ & 25 & 29 & 04 \\
\hline 21. & Tetracyclin & $\mathrm{T}(30 \mu \mathrm{g})$ & 21 & 26 & 05 \\
\hline 22. & Sulphazidime & $\mathrm{Sz}(25 \mu \mathrm{g})$ & 12 & 17 & 04 \\
\hline 23. & Chloramphenicol & $\mathrm{C}(30 \mu \mathrm{g})$ & 18 & 21 & 03 \\
\hline
\end{tabular}

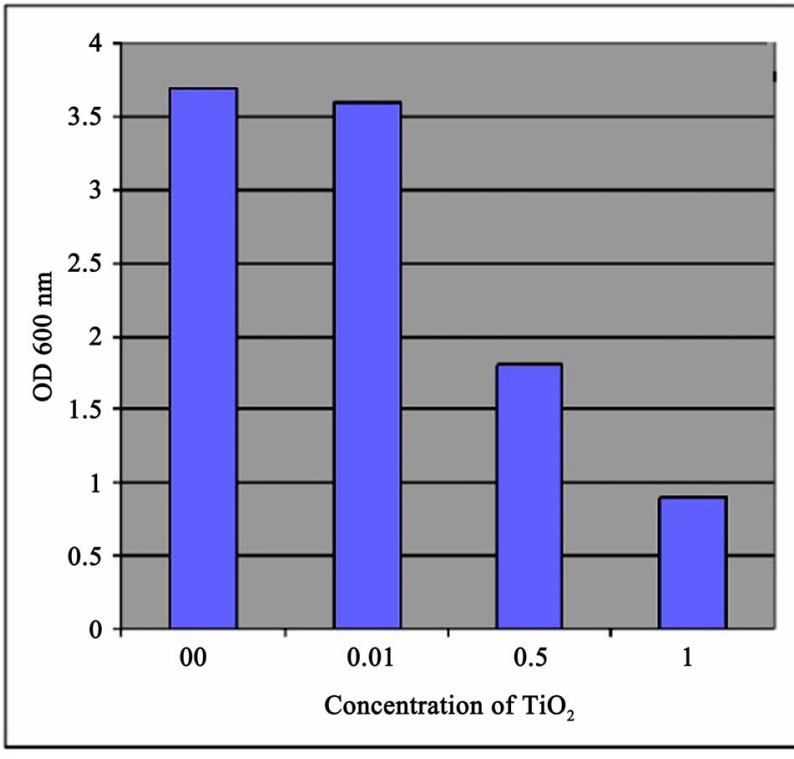

Figure 3. MRSA growth at different concentrations of $\mathrm{TiO}_{2}$.

nanoparticle are cosmetic ingredient has drawn the attention of scientists because of its extensive pharmaceutical properties. In different phases, clinical trials, no toxicity except mild dehydration was observed when taken at doses as high as g/day and it is reported as an attractive choice for many disease therapies.

Recently some metal nanoparticles have been evaluated for increasing the antibacterial activities of different antibiotics. Several investigations have suggested the possible mechanisms involving the interaction of nanomaterials with the biological molecules. It is believed that microorganisms carry a negative charge while metal oxides carry a positive charge. This creates an "electromagnetic" attraction between the microbe and treated surface. Once the contact is made, the microbe is oxidized and dead instantly. Generally, it is believed that nanomaterials release ions, which react with the thiol group (-SH) of the proteins present on the bacterial surface. Such proteins protrude through the bacterial cell membrane, allowing the transport of nutrients through the cell wall. Nanomaterials inactivate the proteins, decreasing the membrane permeability and eventually causing the cellular death [19]. In this study using disk diffusion assay we showed that the antibacterial activity of 
beta lactums, cephalosporins, aminoglycosides, glycolpeptides, erythromycin, clindamycin and tetracycline can be increased by $\mathrm{TiO}_{2}$ nanoparticles. Therefore, this compound or its future derivatives have a good potential for combination effect against MRSA.

\section{Conclusions}

The synthesis of nanosize titanium dioxide of $20 \mathrm{~nm}$ was carried out successfully using citric acid and alpha dextrose as double surfactants. The small nanometer scale $\mathrm{TiO}_{2}$ particles which impose several effects that govern its antibacterial action. The antibacterial activities at different concentrations of nano- $\mathrm{TiO}_{2}$ were investigated. The antimicrobial resistance of MRSA against various antibiotics is increased without nano- $\mathrm{TiO}_{2}$ and decreases with nano- $\mathrm{TiO}_{2}$. Need the further work to find out the exact reason to for enhancement of activity of antibiotics in presence of $\mathrm{TiO}_{2}$ nanoparticles.

\section{REFERENCES}

[1] N. De San, O. Denis, M. F. Gasasira, R. De Mendonca, C. Nonhoff and M. J. Struelens, "Controlled evaluation Of The IDI-MRSA Assay for Detection of Colonization by Methicillin-Resistant, Staphylococcus aureus in Diverse Mucocutaneous Specimens," A.J Clin Microbiol, 2007, Vol. 45, No. 4, pp. 1098-1101.

[2] N. Safdar and D. G. Maki, "The Community of Risk Factors for Nosocomial Colonization and Infection with Anti-Microbial-Resistant Staphylococcus aureus, EnteroCoccus, Gramnegative Bacilli, Clostridium Difficile and Candida," Ann Intern Med, Vol. 136, 2002, pp. 834-844.

[3] L. C. Braga, A. A. Leite, K. G. Xavier, J. A. Takahashi, M. P. Bemquerer, E. Chartone-Souza, et al. "Synergic interaction between pomegranate extract and antibiotics against Staphylococcus aureus," Canadian Journal of Microbiology, Vol. 51, No. 7, 2005, pp. 541-547.

[4] G. C. Schito, "The Importance of the Development of Antibiotic Resistance in Staphylococcus aureus," Clin Microbiol Infect, Vol. 12, Suppl. 1, 2006, pp. 3-8.

[5] S. Gibbons, "Phytochemicals for Bacterial Resistance. Strengths, Weaknesses and Opportunities," Planta Med, Vol. 74, No. 6, 2008, pp. 594-602.

[6] G. D. Wright, "Resisting Resistance: New Chemical Strategies for Battling Superbugs," Chemistry and Biology, Vol. 7, No. 6, 2000, pp. R127-R132.

[7] X. Wu, H. Liu, J. Liu, K. N. Haley, J. A. Treadway, J. P. Larson, et al., "Immunofluorescent Labeling of Cancer Marker Her2 and Other Cellular Targets with Semiconductor Quantum Dots," Nat Biotechnol, Vol. 21, No. 1,
2003, pp. 41-46.

[8] J. D. Fortner, D. Y. Lyon, C. M. Sayes, A. M. Boyd, J. C. Falkner, E. M. Hotze, Alemany et al., "C-60 in Water: Nanocrystal Formation and Microbial Response," Environ Sci Technol, Vol. 39, No. 11, 2005, pp. 4307-4316.

[9] P. Li, J. Li, Q. Wu and J. Li, "Synergistic Antibacterial Effects of Lactum Antibiotic Combined with Silver Nanoparticles," J. Nanotechnol, Vol. 16, No. 9, 2005, pp. 1912-1917.

[10] A. M. Smith, H. Duan, M. N. Rhyner, G. Ruan and S. A. Nie, "Synthesis of Gold Nanoparticles Bearing the Bioconjugation," Phys Chem Chem Phys, Vol. 8, 2006, p. 3895.

[11] G. J. Kearns, E. W. Foster and J. E. Hutchison, "Substrates for Direct Imaging of Chemically Functionalized $\mathrm{SiO}_{2}$ Surfaces by Transmission Electron Microscopy," Anal Chem, Vol. 78, 2006, p. 298.

[12] P. Mulvaney, "Surface Plasmon Spectroscopy of Nanosized Metal Particles Langmuir," Vol. 12, 1996, p. 788.

[13] T. Sungkaworn, W. Triampo, P. Nalakarn, D. Triampo, I. M. Tang, Y. Lenbury, et al. "The Effects of $\mathrm{TiO}_{2}$ Nanoparticles on Tumor Cell Colonies: Fractal Dimension and Morphological Properties," Int J Biomed Sci, Vol. 2, No. 1, 2007, pp. 67-74.

[14] M. Cho, H. Chung, W. Choi, et al., "Different Inactivation Behaviors of MS-2 Phage and Escherichia coli in $\mathrm{TiO}_{2}$ Photocatalytic Disinfection," Appl. Eniron. Microbiol., Vol. 71, 2005, pp. 270-275.

[15] A. Fujishima, N. R. Tata and A. T. Donald, "Titanium Dioxide Photocatalysis," J. Photochem. Photobiol. C. Photochem. Rev., Vol. 1, 2000, pp. 1-21.

[16] K. Shiraishi, H. Koscki, T. Tsurumoto, et al., "Antimicrobial Metal Implant with a $\mathrm{TiO}_{2}$-Conferred Photocatalytic Bactericidal Effect against Staphylococcus aureus," Surf. Inter. Anal., Vol. 41, 2008, pp. 17-21.

[17] NCCLS, "Performance Standards for Antimicrobial Susceptibility Testing," 12th Informational Supplement M100-S12, National Committee for Clinical Laboratory Standards, Villanova, PA. 2002.

[18] B. Shopsin, M. Gomez, S. O. Montgomery, D. H. Smith, M. Waddington, D. E. Dodge, D. A. Bost, M. Riehman, S. Naidich and B. N. Krieswirth, "Evalution of Protein A Gene Polymorphic Region DNA Sequencing for Typing of Staphylococcus aureus Strains," J. Clin. Microbiol, Vol. 37, 1999, pp. 3556-3563.

[19] H. Zhang and G. Chen, "Potent Antibacterial Activities of $\mathrm{Ag} / \mathrm{TiO}_{2}$ Nanocomposite Powders Synthesized by a One-Pot Sol-Gel Method," Environ Sci Technol, Vol. 43, No. 8, 2009, pp. 2905-2910. 